\title{
DMITRII NIKOLAEVICH ZUBAREV
}

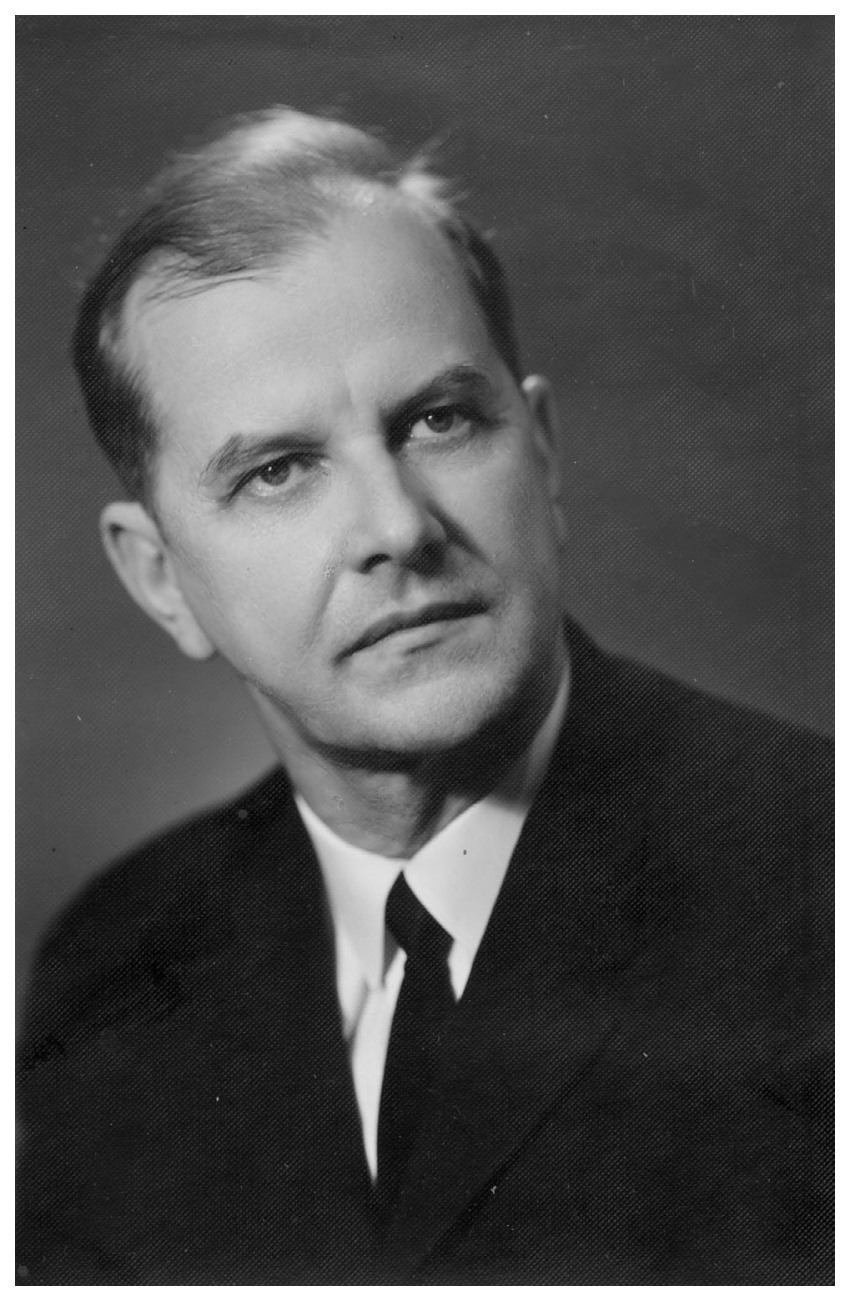

DOI: $10.1134 /$ S0040577918010014

This issue is dedicated to the centennial of the birth of the

Honored Scientist of the Russian Federation,

Doctor of Physical and Mathematical Sciences, Professor

\section{Dmitrii Nikolaevich Zubarev}

Translated from Teoreticheskaya i Matematicheskaya Fizika, Vol. 194, No. 1, pp. 3-4, January, 2018. 